\title{
REGRESSION STUDY ON PLANT DENSITY AND WEED ON THE TRAITS OF DIFFERENT RAPESEED GENOTYPES IN DARAB REGION
}

\author{
Ali Rastegar ${ }^{1}$, Shahram Sharafzadeh ${ }^{1 *}$, Mahdi Zare ${ }^{1}$, Korosh Ordookhani ${ }^{1}$, Omid Alizadeh ${ }^{2}$

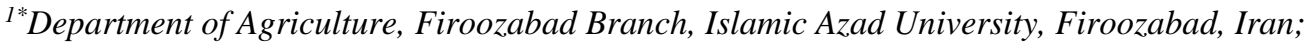 \\ ${ }^{2}$ Department of Agriculture, Shiraz, Branch, Islamic Azad University, Shiraz, Iran; \\ 1*Corresponding author Shahram Sharafzadeh, email: Shahramsharafzadeh@ hotmail.com;
}

Received November, 2018; Accepted December, 2018; Published January, 2019;

DOI: https://doi.org/10.31407/ijees9109

UOI license: http://u-o-i.org/1.01/ijees/29065933

\begin{abstract}
In order to study the application of mathematical models in the analysis of the effect of planting density and weed interference on agronomic traits of different rapeseed genotypes, indicators including physiological feature, morphological feature, components and compounds of components of experimental rapeseed genotypes, in the terraces, which were broken twice, in the form of pilot plan of blocks ,complete randomized, with 3 replications was conducted in Fars province (Darab city, Farrag district) in 2012-2013 (two years). The results of stepwise regression of grain yield (as dependent variable) on 12 agronomic traits were presented for two years. The results confirmed that pod weight and 1000-grain weight could well predict performance changes. In order to interpret the relationships between traits and grouping them, factor analysis was used based on these relationships. Factor analysis was carried out using principal components method on the traits studied in this experiment and the factors were given to Vermax 1 for better justification. In this analysis, the three main and independent factors justify a total of $88.48 \%$ of the total variance.
\end{abstract}

Keywords: Rapeseed, Morphological feature, Density, Weed, Variety, Regression, Correlation Coefficient 